\title{
Particleboard Manufactured from Rubberwood RRIM 2002 Clone Planted with Different Fertilizer Treatment
}

\author{
Syeed SaifulAzry Osman Al Edrus, Paridah Md Tahir, Chuah Teong Guan, Lee Seng Hua, Juliana \\ Ab Halip, Lee Ching Hao
}

\begin{abstract}
This work focus on the effects of SRF (Slow Release Fertilizer) + NPK fertilizer rates on the properties of rubberwood particleboards produced. The particleboards were fabricated using rubber tree trial clone RRIM 2002. RRIM 2002 clone still in trial plot with age of 4-year old and classified as Latex Timber Clone which estimated to produce large wood volume and also better latex yield. The properties of particleboard were categorized and evaluated based on fertilizer treatment applied on RRIM 2002 clone tree: T1 (SRF + NPK at normal rate), T2 (SRF $+1.5 x$ NPK at normal rate), T3 (SRF + 2.0 x NPK at normal rate $)$ and T4 (SRF + 2.5 x NPK at normal rate, control (NPK at normal rate). The resin used for particleboard fabrication was urea formaldehyde (UF) (63.9\% solid) type E1. The resin content is $10 \%$. The thickness of board is $10 \mathrm{~mm}$ with density $700 \mathrm{kgm}^{-3}$. The particleboards were fabricated and assessed in accordance to Japanese Industrial Standard for Particleboard (JIS A 5908-2003). The properties that been assessed were on modulus of elasticity (MOE), modulus of rupture (MOR), internal bonding (IB), thickness swelling (TS) and water absorption (WA). From this study, it is found that fertilizer treatment influences the particle recovery and performance of particleboard especially on dimensional stability and internal bonding properties which significantly affected. The MOR and MOE of particleboard made from rubber trees that treated with SRF-NPK fertilizer showed better performance compared to that of with NPK fertilizer alone (control), however, the differences were not significant. In term of $I B$, no specific trend was observed. Lastly, for dimensional stability (TS and WA), particleboard produced from SRF-NPK fertilizer reduced the board stability when subjected to cold water soak.
\end{abstract}

Index Terms: Particleboard, Urea formaldehyde, RRIM 2002, Rubberwood, Fertilizer

Revised Manuscript Received on July 05, 2019.

Syeed Saifulazry Osman Al Edrus, Institute of Tropical Forestry and Forest Products (INTROP), Universiti Putra Malaysia, 43400 UPM Serdang, Selangor Darul Ehsan, Malaysia. Corresponding author. Email saifulazry@upm.edu.my

Paridah Md Tahir, Institute of Tropical Forestry and Forest Products (INTROP), Universiti Putra Malaysia, 43400 UPM Serdang, Selangor Darul Ehsan, Malaysia. Corresponding author.Email parida@upm.edu.my

Chuah Teong Guan, Institute of Tropical Forestry and Forest Products (INTROP) and Faculty of Engineering, Universiti Putra Malaysia, 43400 UPM Serdang, Selangor Darul Ehsan, Malaysia

Lee Seng Hua, Institute of Tropical Forestry and Forest Products (INTROP), Universiti Putra Malaysia, 43400 UPM Serdang, Selangor Darul Ehsan, Malaysia

Juliana Ab Halip, Faculty of Technology Management and Business, Universiti Tun Hussein Onn Malaysia, 84600 Pagoh, Johor Darul Takzim, Malaysia

Lee Ching Hao, Institute of Tropical Forestry and Forest Products (INTROP), Universiti Putra Malaysia, 43400 UPM Serdang, Selangor Darul Ehsan, Malaysia

\section{INTRODUCTION}

Malaysia is currently experiencing problems in the supply of tropical hardwoods as raw materials for wood-based industries. Thus the alternative timber resources are needed to resolve the issue [1]. Intensive forestry programs are among the action taken by industries and government to address this problem [2]. Plantation forestry using fast growing species has been adopted in many countries to supply the raw material for wood-based industry such as particleboard and medium density fibreboard (MDF) and also to reducing on natural pressure [3]. For the last few decades, Malaysia wood-based industries relies on rubberwood as the main source due to its excellent machining and wood properties. [4]. In the past, rubberwood was considered to have no significant economic value. It is only a traditional source of fuel wood for domestic use and charcoal manufacture [5]. However, with the fast depleting supply and the escalating price of tropical hardwoods in the late 1970, there was an urgency to identify alternative sources to sustain the export-oriented timber industries in Malaysia. Besides, during that time, the rubberwood considered as abundant resources from rubber estate that commercially planted in huge area throughout the country. On that note, it's the best candidate to become source for wood -based industry [6]. Intensive researches on the results of research findings were disseminated through publications, seminar and workshops [7].

A Rubberwood tree from the basis of the Rubberwood Research Institute of Malaysia (RRIM) breeding program was started in 1982. Since then, the Institute has produced six series of clone i.e. RRIM 500 series, RRIM 600 series, RRIM 700 series, RRIM 800 series, RRIM 900 series and recently released clones RRIM 2000 series. In commercial scale, Prang Besar (PB) is widely planted. The RRIM 2000 series clones show that there are several fast-growing clones with potential for timber production as well as latex yield. Besides the breeds factor, soil nutrients also play roles in tree growth and timber properties. Most tropical soils are highly weathered, and levels of $\mathrm{P}, \mathrm{Ca}, \mathrm{Mg}, \mathrm{Zn}, \mathrm{S}, \mathrm{N}, \mathrm{K}, \mathrm{Cu}$, and $\mathrm{B}$ are low or very low [8]. For tree growth, N, P and K play a vital a role and it is very crucial to ensure these nutrients have enough amount to be consume by the trees. 
The most common practice is by supplying certain amount of NPK fertilizer. Hence, the variation of nutrients in the soil and uptake rates by the trees will affect tree growth performance and its wood properties [9]. The estimated mean total wood volume ranged between 0.81 to 1.87 cubic meter per tree at 14 years old [10]. According to Gnanaharan and Dhamodaran [11], rubberwood possesses medium strength properties. The moderate strength properties of rubberwood make it suitable for most of the wood composite making. In Malaysia, rubberwood total planted area around 1.63 million hectares and $70 \%$ of it owned by smallholdings [12].

In all composites products such as particleboard, medium density fibreboard, flakeboard, etc, the wood density was the vital factor that influences the properties of the products [13 Moslemi]. In fact, in many occasion the wood density will be the indicator to predict the performance of the products. This however is not necessarily true due to many other factors, which also influence the strength of the wood such as wood maturity stage and fibre properties [14 Pazd]. Particleboard is a panel product produced by compressing small wood particles while simultaneously bonding them with an adhesive. It is widely used in the manufacture of furniture, cabinets and floor underlayment in home construction. At present, particleboard manufacturing industries in Malaysia are much more dependent on rubberwood as their raw material. It has been reported that at least 4 out of 7 particleboard mills in the country utilizing solely rubberwood in their production with total installed capacity of approximately $1530 \mathrm{~m}^{3}$ / day [15]. In this study, wood from rubber tree RRIM 2002 clone that fertilized with different rates of fertilizer were used to produce particleboard. The effects of these different fertilizer regime to the performance of particleboard were investigated and studied.

\section{MATERIALS AND METHODOLOGY}

\section{A. Materials summary}

The study was used wood from trial rubber trees RRIM 2002 Clone with age 4-year old and planted at 1100 trees per ha which collected from RRIM station in Tok Dor Besut Terengganu, Malaysia. The rubber tree trial clone was fertilized using SRF and at 4 different rates of NPK fertilizer: $\mathrm{T} 1$ (SRF + NPK at normal rate), T2 (SRF + $1.5 \times \mathrm{NPK}$ at normal rate), T3 (SRF + $2.0 \times \mathrm{NPK}$ at normal rate) and T4 $(\mathrm{SRF}+2.5 \times \mathrm{NPK}$ at normal rate). The control plot for trial rubber tree was fertilized with normal rates of NPK fertilizer without using any SRF.

\section{B. Preparation of Particles}

The trees were felled from each of variables and cut into billet size. The samples were chipped using Pallman chipper and air- dried for 24 hours before flaked in Pallman flaker machine. The particles were screened using screener vibrator and only particle with $0.5-2.0$ were used. The particles were oven-dried at $103{ }^{\circ} \mathrm{C} \pm 2{ }^{\circ} \mathrm{C}$ until moisture content $\leq 6 \%$. The particle size $0.5-1.0 \mathrm{~mm}$ and $1.0-2.0 \mathrm{~mm}$ were combined then further used for the particleboard manufacturing. homogenous. The whole particles for each size than weighted to investigate particle recovery.

\section{Manufacture of Particleboard}

The particleboards with size 340 X 340 X 10 mm were manufactured. Three replicates of particleboard with density of $500 \mathrm{kgm}^{-3}$ and $700 \mathrm{kgm}^{-3}$ were made from each of variables. The particles blended and sprayed with Urea Formaldehyde (E1) (solids 65\%) at $10 \%$ resin content. The ammonium chloride as hardener was used at $1 \%$ of resin content and wax at $1 \%$ level. The sprayed particles were formed to produce homogenous mat and cold pressed for 5 minutes. The formed mats were pressed under Tahei oil heated hydraulic press for 7 minutes at $170{ }^{\circ} \mathrm{C}$ to $10 \mathrm{~mm}$ thickness. The boards placed in conditioning room for 3 days before cut into testing specimen. The targeted MC of the board is $10 \%$.

\section{Evaluation of particleboard performance}

The boards were trimmed and conditioned for 3 days at 23 ${ }^{\circ} \mathrm{C}$ and $50 \%$ relative humidity. The boards then cut into specimen sizes and evaluated for strength and dimensional properties according to the Japanese Industrial Standard, JIS A 5908-2003: strength (MOR), stiffness (MOE), internal Bonding (IB), thickness swelling (TS) and water absorption (WA). The bending (MOR, MOE) and internal bond test on particleboard were conducted using Instron Universal Testing Machine Model 4204.

\section{RESULTS AND DISCUSSION}

\section{A. Particles recovery}

Table 1 shows screening analysis of particle recovery from RRIM 2002 clones wood fertilized with different fertilizer treatment. It indicates the particle size and distribution. Referring to table, the particles distributed the most in 1.0 $2.0 \mathrm{~mm}$ size. There are different trends were observed for particle size from less $1.0 \mathrm{~mm}$ and more $1.0 \mathrm{~mm}$ categories. For groups less than $1.0 \mathrm{~mm}(<0.5 \mathrm{~mm}$ and $0.5-1.0 \mathrm{~mm})$, decrement trend was observed as the wood fertilized with higher rates. In contrast, generally, groups of size greater than $1.0 \mathrm{~mm}(1.0-2.0 \mathrm{~mm}$ and $>2.0 \mathrm{~mm})$ have more particles as the rate of fertilizer increase.

Table 1: Screening analysis to classify the particle size.

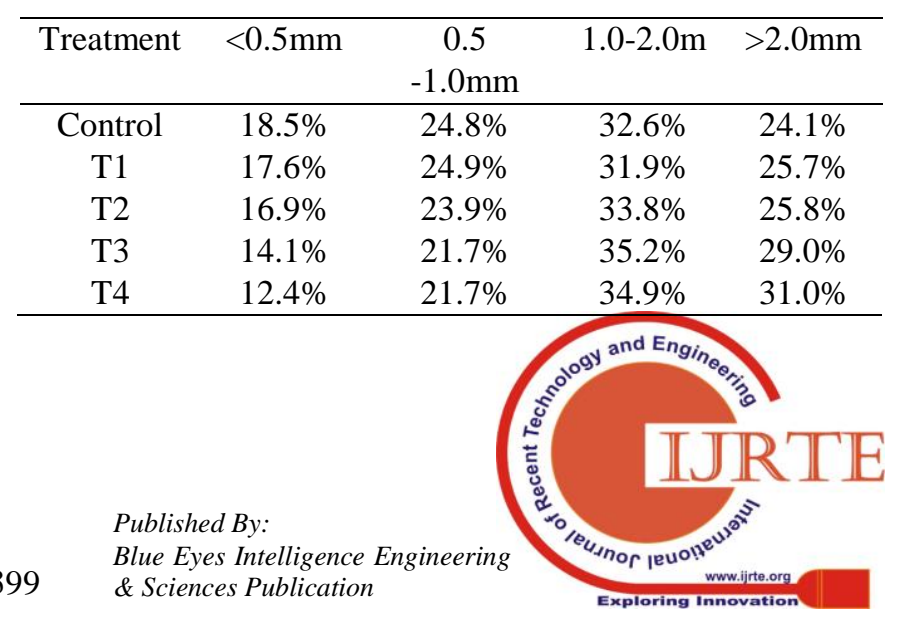




\section{B. Particleboard performance}

The analysis of variance (ANOVA) shown in Table 2 indicates the interaction of board density between treatments have no significant on bending properties (MOR and MOE) but significant for TS and very significant for IB and WA.

Table 2: Summary of ANOVA for interaction board density between treatments

\begin{tabular}{lccccc}
\hline $\begin{array}{l}\text { Source of } \\
\text { variance }\end{array}$ & MOR & MOE & IB & TS & WA \\
\hline $\begin{array}{l}\text { Df } \\
\text { Significant }\end{array}$ & 4 & 4 & 4 & 4 & 4 \\
level & n.s & n.s & $* *$ & $*$ & $* *$ \\
\hline $\begin{array}{l}\text { n.s }=\text { Not significant at } \mathrm{p}>0.05 ; * \text { S Significant at } \mathrm{P}<0.1 ; * *=\text { very } \\
\text { significant at } \mathrm{p} \leq 0.01\end{array}$
\end{tabular}

Table 3 gives the static bending properties (MOR and MOE) of particleboard produced. The performance of board influenced by various factor such as moisture content, particle size, resin distribution, wood density, board density etc. The most important characteristic of wood species affects its suitability for particleboard manufacture is its wood density [16].

Table 3: Effect of wood with different fertilizer treatment on static bending properties of particleboard

\begin{tabular}{ccccc}
\hline Treatment & \multicolumn{2}{c}{ MOR (MPa) } & \multicolumn{2}{c}{ MOE (MPa) } \\
& $\begin{array}{c}500 \\
\left(\mathrm{kgm}^{-3}\right)\end{array}$ & $\begin{array}{c}700 \\
\left(\mathrm{kgm}^{-3}\right)\end{array}$ & $\begin{array}{c}500 \\
\left(\mathrm{kgm}^{-3}\right)\end{array}$ & $\begin{array}{c}700 \\
\left(\mathrm{kgm}^{-3}\right)\end{array}$ \\
\hline Control & $7.48^{\mathrm{a}}$ & $21.0^{\mathrm{a}}$ & $888^{\mathrm{a}}$ & $2022^{\mathrm{a}}$ \\
T1 & $9.06^{\mathrm{a}}$ & $20.8^{\mathrm{a}}$ & $1039^{\mathrm{a}}$ & $2197^{\mathrm{a}}$ \\
T2 & $8.96^{\mathrm{a}}$ & $23.3^{\mathrm{a}}$ & $985^{\mathrm{a}}$ & $2366^{\mathrm{a}}$ \\
T3 & $9.19^{\mathrm{a}}$ & $21.8^{\mathrm{a}}$ & $1141^{\mathrm{a}}$ & $2201^{\mathrm{a}}$ \\
T4 & $7.64^{\mathrm{a}}$ & $21.6^{\mathrm{a}}$ & $956^{\mathrm{a}}$ & $2194^{\mathrm{a}}$
\end{tabular}

Means with the same letter in each column are not significantly different at $\mathrm{p} \leq 0.05$

\section{Modulus of rupture (MOR) and modulus of elasticity (MOE)}

As shown in Table 3, particleboards made from rubberwood that had been applied with SRF + NPK show little improvement compare to that with NPK only (control). However, the differences of both MOR and MOE were no significant regardless fertilizer treatment. The mechanical properties of wood was strongly correlated to clone inheritance than fertilizer treatment [17]. Since all boards manufactured from same rubberwood clone: RRIM 2002, thus, it explains the insignificant differences in MOE and MOR of particleboard produced.

\section{Internal Bonding (IB)}

The average results of internal bonding strength are presented in Table 4 . The IB of board ranged from 0.11 to 2.03 MPa. In general, particleboard made from rubber trees that have been applied with NPK fertilizer (control) has lower IB value compare to that with NPK- SRF mix fertilizer.
However, no specific trend was observed in term of fertilizer rates effect.

Table 4: Internal bonding properties of particleboard

\begin{tabular}{ccc}
\hline Treatment & \multicolumn{2}{c}{ Internal Bond $(\mathrm{MPa})$} \\
& $500\left(\mathrm{kgm}^{-3}\right)$ & $700\left(\mathrm{kgm}^{-3}\right)$ \\
\hline Control & $0.11^{\mathrm{c}}$ & $1.78^{\mathrm{ba}}$ \\
T1 & $0.54^{\mathrm{a}}$ & $1.81^{\mathrm{a}}$ \\
T2 & $0.31^{\mathrm{b}}$ & $2.03^{\mathrm{ba}}$ \\
T3 & $0.29^{\mathrm{cb}}$ & $1.41^{\mathrm{b}}$ \\
T4 & $0.19^{\mathrm{cb}}$ & $1.77^{\mathrm{ba}}$ \\
\hline
\end{tabular}

Means followed with the same letter in the same column are not significantly different at $\mathrm{p} \leq 0.05$.

\section{Dimensional stability}

In this study, the dimensional stability properties of the board were expressed by thickness swelling and water adsorption. The value of TS and WA were shown in table 5 .

Table 5: Effect of fertilizer treatment on dimensional stability of particleboard

\begin{tabular}{ccccc}
\hline Treatment & \multicolumn{2}{c}{ TS (\%) } & \multicolumn{2}{c}{ WA (\%) } \\
& $\begin{array}{c}500 \\
\left(\mathrm{kgm}^{-3}\right)\end{array}$ & $\begin{array}{c}700 \\
\left(\mathrm{kgm}^{-3}\right)\end{array}$ & $\begin{array}{c}500 \\
\left(\mathrm{kgm}^{-3}\right)\end{array}$ & $\begin{array}{c}700 \\
\left(\mathrm{kgm}^{-3}\right)\end{array}$ \\
\hline Control & $14.3^{\mathrm{c}}$ & $21.6^{\mathrm{b}}$ & $53.1^{\mathrm{c}}$ & $37.2^{\mathrm{b}}$ \\
T1 & $21.5^{\mathrm{a}}$ & $27.8^{\mathrm{a}}$ & $92.4^{\mathrm{b}}$ & $67.1^{\mathrm{a}}$ \\
T2 & $17.8^{\mathrm{b}}$ & $27.9^{\mathrm{a}}$ & $96.6^{\mathrm{ba}}$ & $63.6^{\mathrm{a}}$ \\
T3 & $20.1^{\mathrm{a}}$ & $28.0^{\mathrm{a}}$ & $98.0^{\mathrm{a}}$ & $64.7^{\mathrm{a}}$ \\
T4 & $20.8^{\mathrm{a}}$ & $30.3^{\mathrm{a}}$ & $93.8^{\mathrm{b}}$ & $71.5^{\mathrm{a}}$
\end{tabular}

Means with the same letter in each column are not significantly different at $\mathrm{p} \leq 0.05$.

Wood based composite panel such as particleboard being hygroscopic in nature will absorb moisture when exposed to water vapor or liquid water and subsequently diminishing its dimensional stability. This will cause particle separation due the bond deterioration, thus contribute to the overall thickness swelling in the board. The lower value of the thickness swelling, the better the dimensional stability of the board. As shown in table 5 show the range of thickness swelling was from $14.30 \%$ to $30 \%$. The particleboard higher density obtain lower water absorption and thickness swelling. This is attributed by higher compaction ratios in higher density board to Vital et al. [18] Higher compaction means the board is less porous because of the increase in the amount of wood material in a constant volume [19]. Thus, water penetration in higher density board occurs at a slower rate than in the lower density board where there are move voids and gaps through which the water can easily penetrate. In term of fertilizer rates effects, particleboard from wood treated with NPK-SRF fertilizer absorbs more water and less stable than from wood treated with NPK only (control) as indicate by TS and WA values. The difference was highly significant. In contrast, fertilizer rates seems not give so much effect on board dimensional stability as all the values among particleboard 
made using NPK-SRF fertilizer - treated wood in the same group which indicates insignificant differences.

\section{CONCLUSION}

For this study, as overall conclusion, fertilizer treatment influences the particle recovery and performance of particleboard especially on dimensional stability and internal bonding properties which significantly affected. In fact, by application of SRF and variation of fertilizer rates in fertilizer treatment seems correlates with overall properties of particleboards produced. The mechanical properties (MOR and MOE) shows relatives small improvement with insignificant differences. No specific trend was observed for internal bonding properties. In term of dimensional stability, the application of SRF and increment of fertilizer rates directly reduce the stability of the board after subjected to cold water soak.

\section{ACKNOWLEDGMENT}

Many thanks to Nik Hazlan Nik Hashim and Fakharuddin Supa'at and staf of Malaysia Rubber Board for their helps on completion of this project. This work also supported by Institute of Tropical Foretry and Forest Products (INTROP), Universiti Putra Malaysia.

\section{REFERENCES}

1. K. Jusoff, M.M. Yusoff, and N. H. Mohd Ali, "Spectral signatures of leaf fall diseases in Hevea brasiliensis using a handheld spectroradiometer," Modern Applied Science, vol.4, 2011, 78-84.

2. M.S.H. Othman, and A.R. Abdul Samad, "A preliminary study of strategic competitiveness of MDF industry in Peninsular Malaysia by using SWOT analysis," International Journal of Business and Management, vol.4, 2009, 205-214.

3. J.L. Colodette, C.M. Gomes, F.J. Gomes, and C.P. Cabral, "The Brazilian wood biomass supply and utilization focusing on eucalypt," Chemical and Biological Technologies in Agriculture, vol.1, 2014, 25.

4. A. Shigematsu, N. Mizoue, T. Kajisa, and S. Yoshida, "Importance of rubberwood in wood export of Malaysia and Thailand," New Forests, vol. 41, 2011, 179-189.

5. Y.P. Teoh, M.M. Don, and S. Ujang, "Assessment of the properties, utilization, and preservation of rubberwood (Hevea brasiliensis): a case study in Malaysia," Journal of Wood Science, vol.57, 2011, 255-266.

6. J. Ratnasingam, F. Ioras, and W. Lu, "Sustainability of the rubberwood sector in Malaysia," Notulae Botanicae Horti Agrobotanici Cluj-Napoca, vol.39, 2011, 305-311.

7. S.C. Lim, K.S. Gan, and K.T. Choo, "The characteristics, properties and uses of plantation timbers-rubberwood and Acacia mangium," Timber Technology Bulletin, 26, 2003, 1-10.

8. E. Moura, C. Gehring, H. Braun, A. Ferraz Junior, F. Reis, and A. Aguiar, "Improving farming practices for sustainable soil use in the humid tropics and rainforest ecosystem health," Sustainability, vol.8, 2016, 841.

9. R.S. Dharmakeerthi, J.A.S Chandrasiri and V.U. Edirimanne Effect of rubber wood biochar on nutrition and growth of nursery plants of Hevea brasiliensis established in an Ultisol. SpringerPlus volume 1, 2012, Article number: 84.

10. J. Balsiger, J. Bahdon, and A. Whiteman, "The utilization, processing and demand for rubberwood as a source of wood supply," The Food and Agriculture Organization of the United Nations (FAO), Rome: Forestry Policy and Planning Division, 2000.

11. R. Gnanaharan, and T.K. Dhamodaran, "Mechanical properties of rubberwood from a 35-year-old plantation in central Kerala, India," Journal of Tropical Forest Science, vol.6, 1993 , 136-140

12. S.M.W.J. Wee, and K. Singaravelloo, "Income targets and poverty of rubber smallholders in four states of Malaysia," Journal of the Malaysian Institute of Planners, vol.16, 2018, 381-396.

13. Moslemi A.A., Particleboard. Volume 1: Materials. Southern Illinois University Press. London. United Kingdom, 1974, 243 pp.

14. Pazdrowski, W. and Splawa-Neyman, S. Stage rowth of trees and i'ts effect on selected properties of Norway spruce wood (Picea abies (L.) Karst.) Electronic Journal of Polish Agricultural Universities, Forestry, Volume 6, 2003, Issue 2.

15. M.P. Koh, and S. Rahim, "The Malaysian wood based industries: Challenges and Prospects," 4th Conference on Forestry and Forest Products Research, FRIM, 2-4 October, 1997.

16. J.G. Haygreen, and J.L. Bowyer, "Forest Products and Wood Science: An Introduction," The Iowa State University Press, Iowa, 1982, p. 495.

17. J. Xuea, P.W. Clintona, A.C.. Leckiea, and J.D. (). Graham Magnesium fertilizer, weed control and clonal effects on wood stiffnessof juvenile ePinus radiate at two contrasting sites. Forest Ecology and Management 306, 2013, 128-134

18. B.R. Vital, W.F. Lehmann, and R.S. Boone, "How species and board densities affect properties of exotic hardwood particleboards," Forest Product Journal, vol.24, 1974, 37-45.

19. S.H. Lee, Z. Ashaari, W.C. Lum, P.S. H'ng, L.P. Tan, M.J. Chow, E.W. Chai, and K.L. Chin, "Properties of particleboard with oil palm trunk as core layer in comparison to three-layer rubberwood particleboard," Journal of Oil Palm Research, vol.27, 2015, 67-74

\section{AUTHORS PROFILE}

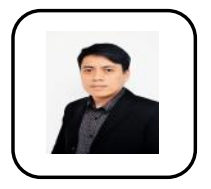

Syeed SaifulAzry Al Edrus is a research officer from Institute of Tropical Forestry and Forest Products, Universiti Putra

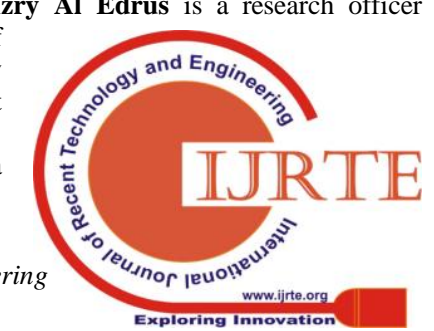


Malaysia, majoring in nanocomposite science. To date, he has published more than 20 articles in numerous journals, book chapters, proceedings etc.

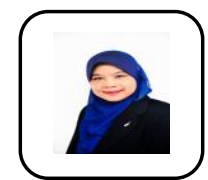

Paridah Md Tahir is a professor from Institute of Tropical Forestry and Forest Products, Universiti Putra Malaysia, majoring in biocomposite science. To date, she has published more than 290 articles in numerous journals, book chapters, proceedings etc.

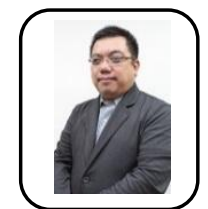

Chuah Teog Guan is a professor from Institute of Tropical Forestry and Forest Products and Faculty of Engineering, Universiti Putra Malaysia, majoring in biopolymer chemistry. To date, he has published more than 300 articles in numerous journals, book chapters, proceedings etc.

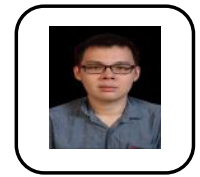

Lee Seng Hua is a research fellow from Institute of Tropical Forestry and Forest Products, Universiti Putra Malaysia, majoring in wood science and technology. To date, he has published more than 80 articles in numerous journals, book chapters, proceedings etc.

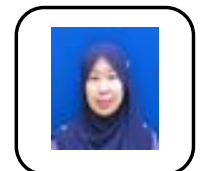

Juliana Abdul Halip is a lecturer from Faculty of Technology Management and Business, Universiti Tun Hussien Onn, majoring in biocomposite science. To date, she has published more than 40 articles in numerous journals, book chapters, proceedings etc.

Lee Ching Hao is a post-doctoral researcher from Institute of Tropical Forestry and Forest Products, Universiti Putra Malaysia, majoring in biocomposite science. 